\title{
Resuscita
in the dental
} practice
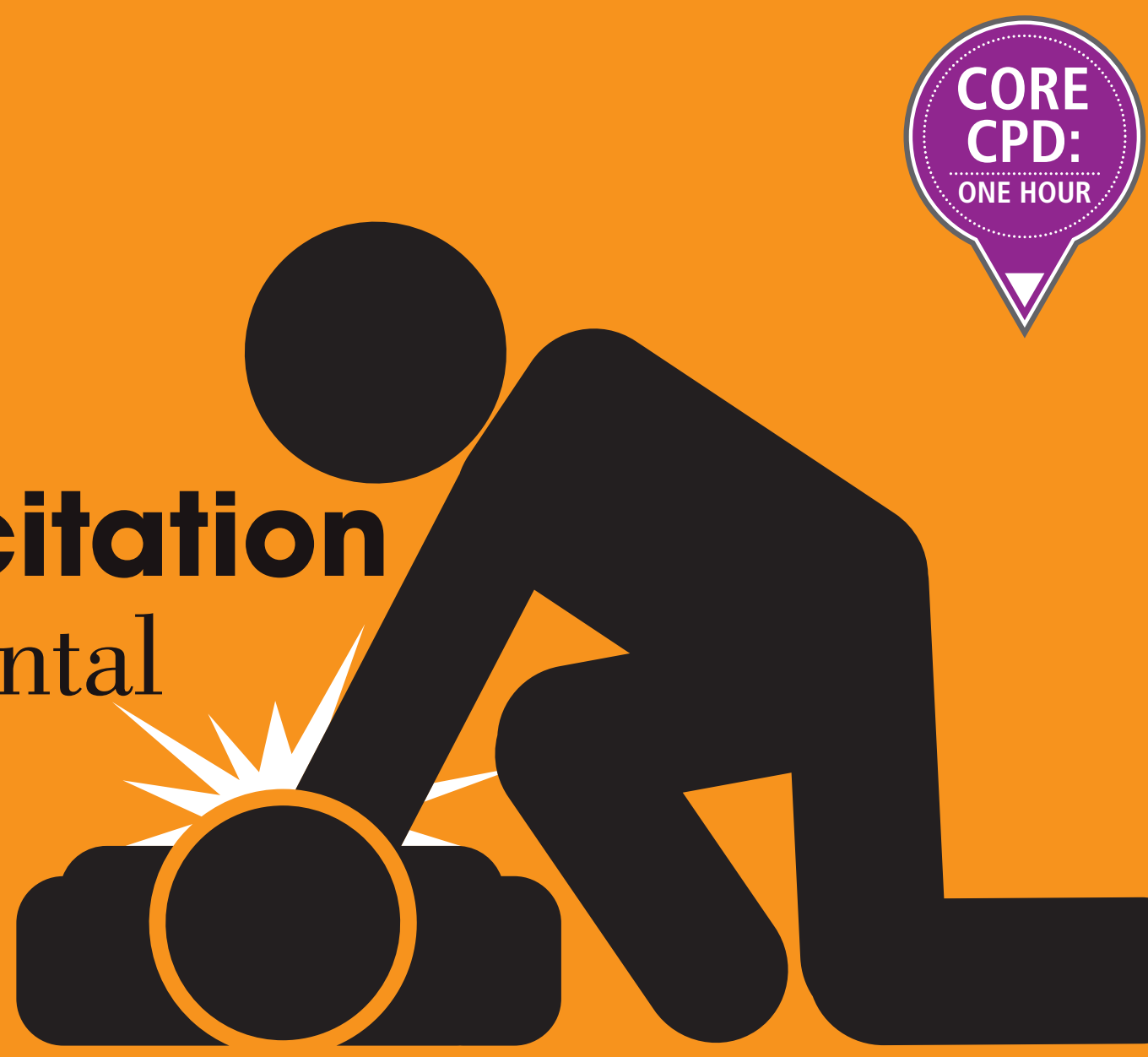

Phil Jevon' looks at the new resuscitation guidelines published in October 2015 and discusses how dental practices should implement them.
Walsall Healthcare NHS Trust, Manor Hospital Walsall

\section{A DUTY OF CARE}

Every dental practice has a duty of care to ensure that an effective and safe service is provided for its patients. The satisfactory performance in a resuscitation attempt in the dental practice has wide-ranging implications in terms of resuscitation equipment, resuscitation training, standards of care, clinical governance, risk management and clinical audit.

The Resuscitation Council (UK) published new resuscitation guidelines in October 2015. The aim of this article is to understand these new guidelines and how dental practices should implement them. It highlights that the AED sign should be clearly displayed and that practices should display the 'Resuscitation in the Dental Practice' poster (Fig. 1) as an aidememoire for the dental team.

\section{GUIDELINES 2015: IMPORTANT MESSAGES}

Promptly assess the unresponsive patient for signs of normal breathing In the first few minutes following a cardiac arrest, the patient may be hardly breathing, or taking infrequent, irregular and slow gasps, often accompanied by a characteristic snoring sound. This is called agonal breathing and it originates from the brain stem, which remains functioning for a few minutes following a cardiac arrest even when deprived of oxygen. Agonal breathing is common in the first few minutes following a cardiac arrest and, if correctly identified as a sign of cardiac arrest, is associated with higher survival rates. ${ }^{1}$

Always be suspicious of cardiac arrest in a patient who presents with seizures: carefully check if the patient is breathing normally

Immediately following cardiac arrest, because cerebral blood flow is reduced to almost zero, a short seizure-like episode may be witnessed that could be confused with epilepsy. Dental staff should be suspicious of cardiac arrest in any patient presenting with seizures.

Minimise delay to starting chest compressions

On confirming cardiac arrest, stay with the patient and start chest compressions immediately while asking colleagues to call 999 for an ambulance and to fetch automated external defibrillator (AED)/resuscitation equipment. If alone, leave the patient, call 999 for an ambulance (consider the use of a speaker phone facility), fetch the AED, switch it on and follow the instructions before starting chest compressions. 
Perform effective chests compressions Deliver compressions to the centre of the chest, at a depth of 5-6 cm, at a rate of 100-120 per minute. Following each chest compression, allow complete recoil of the chest as this will result in improved venous return to the heart (NB avoid leaning forward after each chest compression). As rescuer fatigue can lead to less effective chest compressions, it is advised to change the person performing chest compressions every two minutes - this coincides conveniently with the working of an AED (every two minutes it will ask you to stop CPR while it analyses the ECG). Changing CPR providers should not interrupt the delivery of chest compressions.

As soon as possible switch the AED on and follow the instructions

Combine chest compressions with ventilations

In clinical settings such as dental practices, there are usually good clinical reasons to avoid mouth-to-mouth ventilation; consequently it is rarely used. Perform chest compressions until the ventilation equipment, for example, pocket mask or bag/valve/mask device, arrives. Once ventilation equipment arrives, stop chest compressions and administer two ventilations. Then continue with chest compressions and ventilations at a ratio of 30:2.

\section{Minimise interruptions to chest compressions \\ Only stop CPR if you are certain the patient has recovered and is breathing normally}

Once the paramedics arrive they will advise accordingly.

\section{RESUSCITATION IN THE DENTAL} PRACTICE POSTER

A new 'Resuscitation in the Dental Practice' poster (Fig. 1) which has been endorsed by the British Dental Association (BDA) has been developed, which incorporates the new Resuscitation Council (UK) adult basic life support algorithm. This algorithm should consider displaying the sign, as it will act as a constant reminder where their AED is stored. Some dental practices also display the sign on an external door or window, thus raising local awareness that there is an AED on the premises. To download the AED sign go to https://www.resus.org.uk/defibrillators/ standard-sign-for-aeds/.

\section{'IT HAS BEEN SHOWN THAT DEFIBRILLATION}

\section{WITHIN 3-5 MINUTES OF COLLAPSE CAN PRODUCE}

\section{SURVIVAL RATES AS HIGH AS 50-70\%,}

now includes the use of an AED (there is no longer an automated external defibrillation algorithm). This poster can be printed from the BDJ Team website (PDF) or downloaded from https://www.walsallhealthcare.nhs.uk/ Data/Sites/1/media/documents/health-andsafety/resus.pdf.

\section{IMPORTANCE OF THE AED}

It has been shown that defibrillation within 3-5 minutes of collapse can produce survival rates as high as $50-70 \% .{ }^{4}$ In dental practices, this could be achieved if an AED is immediately available. In the event of a cardiac arrest in a dental practice, as well as ensuring someone has called 999 for an ambulance, send a colleague to fetch the AED (and resuscitation equipment) while starting chest compressions. Each minute of delay to defibrillation reduces the probability of survival to hospital discharge by $10 \%{ }^{5}$

\section{'DENTAL PROFESSIONALS, WHEN RESUSCITATING}

\section{INFANTS AND CHILDREN, SHOULD FOLLOW THE}

\section{ADULT BASIC LIFE SUPPORT SEQUENCE...}

Register the dental practice's AED with the local ambulance service This is highly desirable so that ambulance control dispatchers can direct CPR providers to the nearest AED. ${ }^{2}$ A visible AED sign outside the dental practice would be helpful. ${ }^{3}$

\section{AED SIGN}

The Resuscitation Council (UK) has designed a standard AED sign (Fig. 2) to indicate the presence of an AED. This sign, which has been accepted by the Health and Safety Executive (HSE), helps to reduce delay in locating an AED in an emergency. Dental practices

\section{DEBRIEFING FOLLOWING AN EVENT}

Following an event such as a medical emergency, the Resuscitation Council (UK) ${ }^{6}$ recommends a period of 'debriefing' which will enable dental staff to reflect on how the event was managed and how the patient was treated. Discussion could take place on how a similar event could and perhaps should be managed if it were to happen again.

\section{PAEDIATRIC RESUSCITATION \\ GUIDELINES}

Cardiorespiratory arrest occurs less frequently in children compared with adults, hence both healthcare professionals and lay people are less likely to be involved in paediatric resuscitation. Most cardiorespiratory arrests in children are not caused by a primary cardiac problem but secondary to other causes, mostly respiratory insufficiency. The priority with paediatric resuscitation is, therefore, usually to reoxygenate the child.

The Resuscitation Council (UK) ${ }^{7}$ advises that dental professionals, when resuscitating infants and children, should follow the adult basic life support sequence of 30:2 with the following modifications that make it more suitable for use on children:

- Five initial ventilations before starting chest compressions

- If on your own (very unlikely), perform CPR for approximately one minute before going for help

- Compress the chest by one-third of its depth: in infants this equates to approximately four centimetres depth and in older children five centimetres depth

- Use two fingers to compress the chest in an infant younger one year; use one or two hands for a child older than one year to achieve an adequate depth of compression. 


\section{RESUSCITATION IN THE DENTAL PRACTICE}
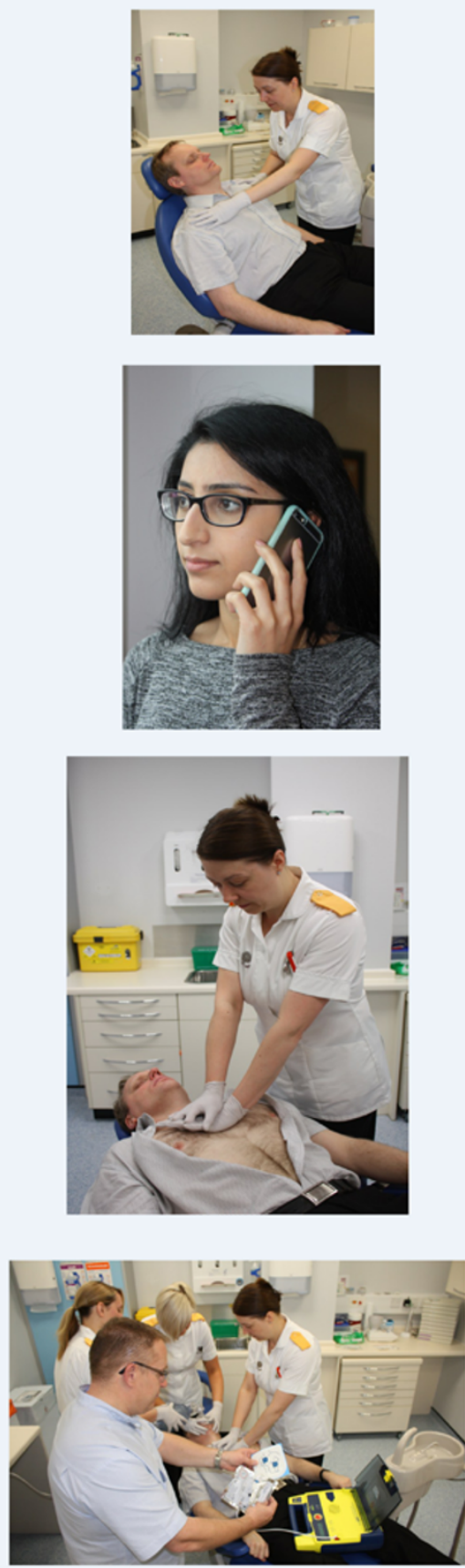
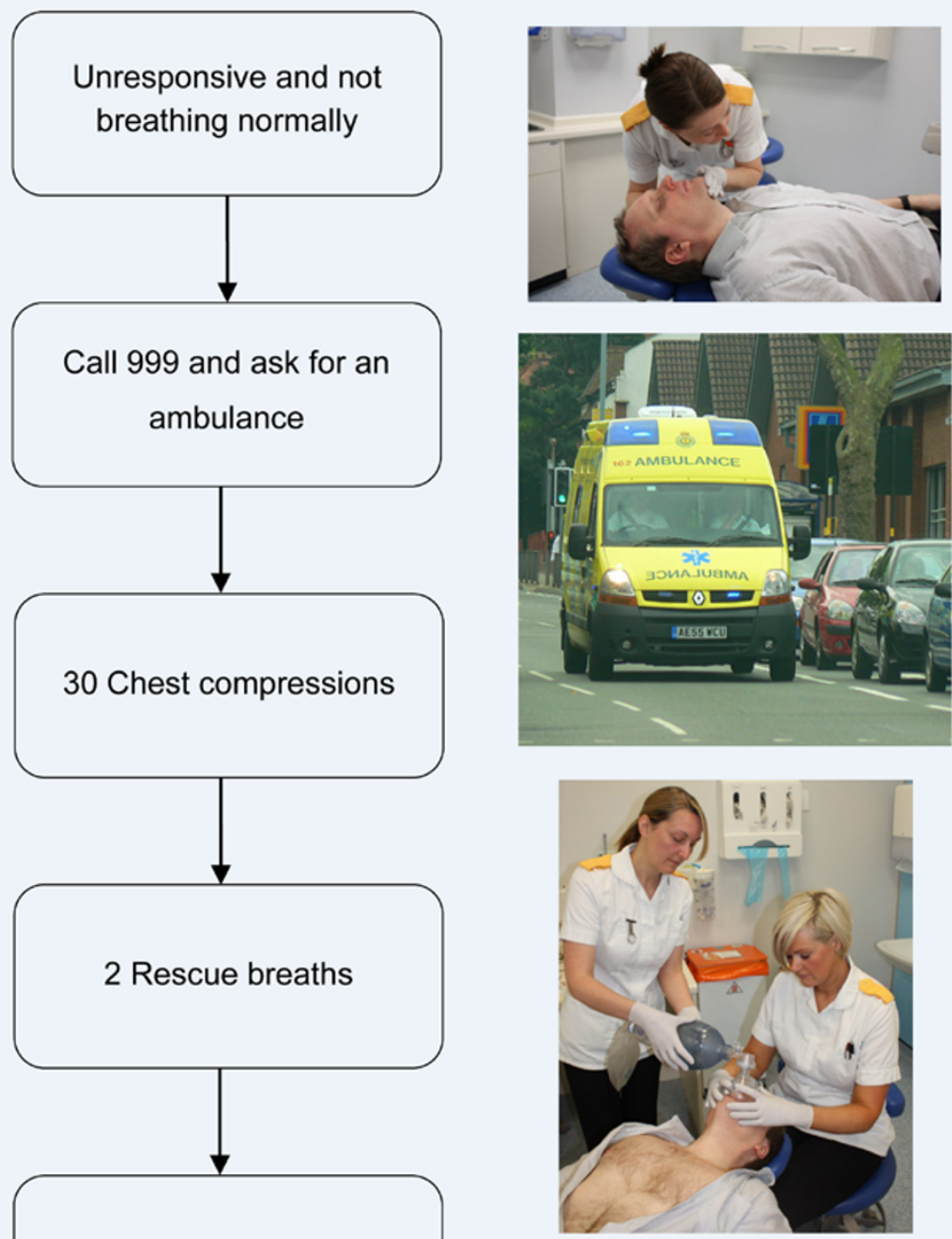

Continue CPR 30:2

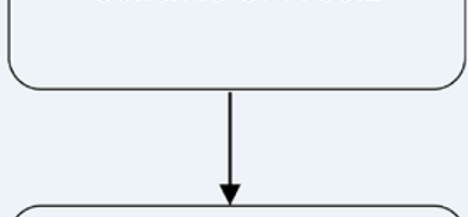

As soon as AED arrives switch it on and follow

\section{instructions}

\section{References}

Jevon P (2013) Medical Emergencies in the Dental Practice 2nd Ed Wiley Blackwell, Oxford

Resuscitation Council UK (2015) Adult basic life support and automated external defibrillation https://www.resus.org.uk/resuscitation-quidelines/adult-basic-life-support-and13/11/2015

Resuscitation Council UK (2015) Primary dental care equipment list https://www.resus.org.uk/quality-standards/primary-dental-care-equipment-list/ accessed 13/11/2015 Acknowledgements

Poster designed as an aid memoir by Phil Jevon Medication Education with the help of Mr N Rashid \& Miss R Joshi ED Consultants, Mrs S Church, Consultant Orthodontist, Steve Webb Clinical Skills Technician and the dental nurses, Walsall Healthcare NHS Trust, Manor Hospital Walsall. UK

Adult basic life support algorithm reproduced with kind permission of the Resuscitation Council (UK), London Ambulance image kindly supplied by WMAS

Simrun Rehsi, Undergraduate BSc Computing for Business (ITMB), Aston University, Birmingham for her IT support 
Defibrillation is rarely needed in children, although it is advised to use paediatric electrode pads for defibrillation of children under eight years of age. If they are not available, adult electrodes placed in an anteroposterior orientation will suffice. ${ }^{6}$

\section{TEAM APPROACH TO RESUSCITATION}

Resuscitation requires a system to be in place to optimise the chances of the patient surviving. This system requires technical and non-technical skills (teamwork, situational awareness, leadership, decision making). ${ }^{6}$ An effective team leader is paramount. Ideally, the dentist should assume the role of team leader, allocating team members specific roles they understand and are able to undertake.

Whether the emergency is in the dental surgery itself, or in another part of the building, it is important to ensure there is 360 degree access to the patient ('Circle of Life'). ${ }^{6}$

\section{Position 1}

Airway \& ventilation - if a bag/valve/mask device is used, then ideally two persons are needed; one to open the airway and ensure a good seal with the mask while a second person squeezes the bag. The person holding the mask on will find sitting on the dentist's stool more comfortable.

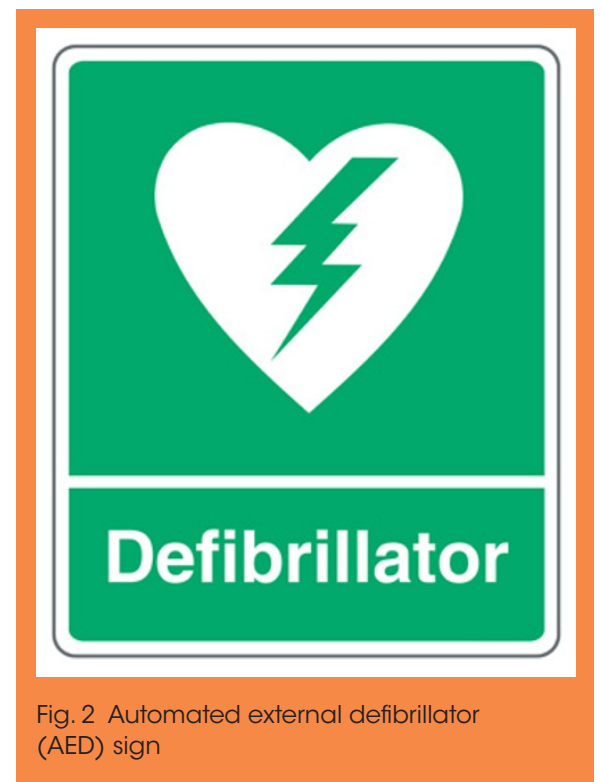

back and overseeing the resuscitation attempt, the dentist will be in a better position to help ensure that the resuscitation attempt runs smoothly, effective resuscitation is provided, appropriate decisions are made and the patient and rescuer's safety is maintained.

\section{PREVENTION OF CARDIAC ARREST}

In the majority of sudden cardiac deaths outside hospital, there is a history of heart

\section{'PROMPT RECOGNITION OF CARDIAC CHEST PAIN}

\section{AND RAPID ACTIVATION OF THE EMERGENCY}

\section{SERVICES WHERE APPROPRIATE REMAINS A}

\section{PRIORITY FOR DENTAL PROFESSIONALS.'}

\section{Position 2}

High quality chest compressions - at patient's left side. The dental chair should be horizontal and at a comfortable height for the person performing chest compressions. Be prepared to alternate with the operator at position 3 to avoid fatigue.

\section{Position 3}

AED use and alternative chest compressions provider (avoiding fatigue) - ideally the opposite side of position 2.

\section{Position 4}

Team leader (usually the dentist) standing at the foot end of the dental chair - by standing disease and warning symptoms (usually chest pain) in the hour preceding cardiac arrest. ${ }^{8}$ The prompt recognition of cardiac chest pain and rapid activation of the emergency services where appropriate remains a priority for dental professionals, as well as ensuring immediate access to an AED.

\section{CONCLUSION}

In the event of a cardiac arrest in the dental practice, dental professionals should ensure a swift, effective and safe resuscitation response to help optimise the chances of the patient surviving. The Resuscitation Council (UK)'s Guidelines 2015 stress the importance of calling 999, performing effective chest compressions and switching on the AED and following its instructions as soon as possible.

1. Lewis M, Stubbs B A, Eisenberg M S. Dispatcher-assisted cardiopulmonary resuscitation: time to identify cardiac arrest and deliver chest compression instructions. Circulation 2013; 128: $1522-$ 1530.

2. Zijlstra J A, Stieglis R, Riedijk F et al. Lay rescuers with AEDs, alerted by text messages, contribute to early defibrillation in a Dutch out-of-hospital cardiac arrest dispatch system. Resuscitation 2014; 85: 1444-1449.

3. Perkins G, Colquhoun M, Deakin C, Handley A, Smith C, Smyth M. Adult basic life support and automated external defibrillation. 2015. Available online at https://www.resus.org.uk/resuscitationguidelines/adult-basic-life-supportand-automated-external-defibrillation/ (accessed January 2016).

4. Valenzuela T D, Roe D J, Nichol G et al. Outcomes of rapid defibrillation by security officers after cardiac arrest in casinos. N Engl J Med 2000; 343: 12061209.

5. Jevon P. Medical emergencies in the dental practice. 2nd ed. Wiley: Oxford, 2013.

6. Deakin C, Brown S, Jewkes F et al. Prehospital resuscitation. 2015. Available online at https://www.resus.org.uk/ resuscitation-guidelines/prehospitalresuscitation/ (accessed January 2016).

7. Resuscitation Council UK. Frequently asked questions: paediatric life support. 2016. https://www.resus.org.uk/faqs/faqspaediatric-life-support/ (accessed January 2016).

8. Hayashi M, Shimizu W, Albert C M. The spectrum of epidemiology underlying sudden cardiac death. Circ Res 2015; 116: 1887-1906.

This article was originally published in the $\mathrm{BDJ}$ on 11 March 2016 in Volume 220 issue 5, pages 261-263.

\section{MEDICAL EMERGENCIES POSTERS}

Did you see our earlier article from Phil Jevon, Updated posters to manage medical emergencies in the dental practice? It was published in BDJ Team in March and is available to read at the following link: http://www.nature.com/ articles/bdjteam201655

bdjteam2016120 